OPEN ACCESS

Edited by:

Antonio Di Franco,

Department of Integrative Marine

Ecology, Italy

Reviewed by:

Manfredi Di Lorenzo,

National Research Council (CNR), Italy

Marisa Vedor,

Centro de Investigacao em Biodiversidade e Recursos Geneticos

(CIBIO-InBIO), Portugal

*Correspondence:

Christopher D. H. Thompson chris.d.h.thompson1@gmail.com

Specialty section:

This article was submitted to

Marine Conservation

and Sustainability,

a section of the journa

Frontiers in Marine Science

Received: 28 November 2020

Accepted: 14 May 2021

Published: 11 June 2021

Citation:

Thompson $\mathrm{CDH}$, Meeuwig JJ,

Brown J, Richardson AJ,

Friedlander AM, Miller PI and Weber SB (2021) Spatial Variation in Pelagic Wildlife Assemblages

in the Ascension Island Marine

Protected Area: Implications for Monitoring and Management.

Front. Mar. Sci. 8:634599.

doi: 10.3389/fmars.2021.634599

\section{Spatial Variation in Pelagic Wildlife Assemblages in the Ascension Island Marine Protected Area: Implications for Monitoring and Management}

\author{
Christopher D. H. Thompson ${ }^{1,2 *}$, Jessica J. Meeuwig', Judith Brown ${ }^{3}$, \\ Andrew J. Richardson ${ }^{3}$, Alan M. Friedlander ${ }^{2,4}$, Peter I. Miller ${ }^{5}$ and Sam B. Weber ${ }^{3,6}$ \\ ${ }^{1}$ Marine Futures Lab, School of Biological Sciences, University of Western Australia, Crawley, WA, Australia, ${ }^{2}$ Pristine Seas, \\ National Geographic Society, Washington, DC, United States, ${ }^{3}$ Conservation Department, Ascension Island Government, \\ Ascension Island, United Kingdom, ${ }^{4}$ Hawai'i Institute of Marine Biology, University of Hawai'i, Kāne'ohe, HI, United States, \\ ${ }^{5}$ Plymouth Marine Laboratory, Plymouth, United Kingdom, ${ }^{6}$ Centre for Ecology and Conservation, College of Life and \\ Environmental Sciences, University of Exeter, Exeter, United Kingdom
}

Bathymetric features such as islands and seamounts, as well as dynamic ocean features such as fronts often harbour rich marine communities. We deployed mid-water baited remote underwater video systems on three expeditions in Ascension Island's Exclusive Economic Zone (EEZ), surveying the waters associated with six different bathymetric and dynamic ocean features: Ascension Island, two shallow seamounts (summits $\leq 101 \mathrm{~m}$ ), one deeper seamount (summit $>250 \mathrm{~m}$ ), apparent fronts, and haphazardly sampled open ocean areas. At Ascension Island, the pelagic assemblage consisted of a moderate proportion of predators and a diverse range of other taxa, including turtles, dolphins, and large non-piscivores. At the two shallow seamounts, sharks, tunas, billfish, and other large pelagic predators formed the vast majority of the assemblage, contributing $>99.9 \%$ of biomass and $>86 \%$ of abundance. At the deeper seamount, the pelagic community was comparatively depauperate, however the functional composition of its assemblage indicated some similarities to the shallow seamounts. Apparent fronts did not significantly differ from random offshore sites for metrics such as total abundance and taxonomic richness. However, they harboured assemblages with more abundant sharks, tunas, and large piscivores than random ocean open locations and these differences may be driven by certain frontassociated species. Our results illustrate that pelagic assemblages vary markedly among different physical and oceanographic features and that seamounts appear particularly important for pelagic predators. The diversity and abundance of the assemblage, as well as the threatened status of many of the species observed, serve to highlight the conservation value of the Ascension Island EEZ. Our results also provide important baseline information of pelagic wildlife assemblages against which the performance of the recently implemented Ascension Island Marine Protected Area can be evaluated. 


\section{INTRODUCTION}

Marine protected areas (MPAs) are a critical tool in the conservation of biodiversity and the effective management of fisheries (Roberts et al., 2005; Lester et al., 2009; Cabral et al., 2020; Di Lorenzo et al., 2020). The 2014 World Parks Congress called for at least $30 \%$ of each marine habitat to be designated within highly protected MPAs (Wenzel et al., 2016). This target is supported by recent reviews investigating the degree to which the scale of protection delivers environmental and socioeconomic outcomes, ranging from protection of biodiversity to maximising fisheries value and yield ( $O$ 'Leary et al., 2016; Waldron et al., 2020). This target, also the basis of the International Union for the Conservation of Nature (IUCN) " $30 \times 30$ " initiative: $30 \%$ of the ocean protected by 2030 (Zhao et al., 2020), represents a substantial increase on the current coverage of $7.4 \%$, with only $2.5 \%$ considered highly protected (Waldron et al., 2020).

With the designation of large MPAs, ecological baselines must be established in order to assess the outcomes of protection. There is a particular need to better understand the status of pelagic species in large MPAs given that the majority of their coverage is in blue water. This poses a considerable challenge as pelagic species are often patchily distributed, respond to dynamic ocean features, and their biology, habitat associations and movements remain relatively little understood compared to coastal species (Angel, 1993). Many pelagic species such as tunas, sharks, and billfish are of high commercial value and have conservative life histories (Collette B.B. et al., 2011). Consequently, their populations are at increased risk and have experienced large declines globally (Juan-Jordá et al., 2011; Dulvy et al., 2014; Roff et al., 2018; Pacoureau et al., 2021). Large reserves have been suggested as refuges for these species (Game et al., 2009; Mee et al., 2017; Letessier et al., 2019), allowing some respite from the pressures in the rest of their global range (Wilhelm et al., 2014). However, the empirical benefits of such refuges remain largely undocumented, primarily due to the lack of longstanding pelagic MPAs in which such protection can be evaluated against the necessary baselines.

Bathymetric and dynamic oceanographic features are known to harbour rich assemblages of pelagic species and are therefore of particular interest in marine spatial planning and reserve implementation. Features such as coasts, islands, reefs, seamounts, and canyons are frequently associated with aggregations of marine wildlife (Yen et al., 2004; Clarke et al., 2011; Bouchet et al., 2015, 2020). Islands often have higher productivity and biodiversity than surrounding waters (Doty and Oguri, 1956; Gove et al., 2016), and seamounts are often hotspots of pelagic biodiversity with higher species richness of commercially caught pelagic species around their summits than in coastal and oceanic areas (Morato et al., 2010). Fronts, eddies, and upwelling areas also drive pelagic species distributions (Queiroz et al., 2012; Scales et al., 2014; Miller et al., 2015; Xu et al., 2017), providing increased foraging opportunities (BenoitBird et al., 2019), increasing productivity (Woodson and Litvin, 2015), and even facilitating the use of different niches (Braun et al., 2019). These physical and oceanographic factors may also interact, increasing their effect and driving the formation of pelagic aggregations (Morato et al., 2016).

In line with existing goals of increased ocean protection, the United Kingdom established the Blue Belt Programme in 2016 (UK Government, 2017). This initiative outlines the UK government's commitment to provide long term protection for over four million square kilometres of marine environment across its Overseas Territories, including an improved scientific understanding of the marine environment in these territories and the development and implementation of sustainable, long term, evidence-based marine management strategies. In August 2019, the administration of Ascension Island in the tropical South Atlantic announced its commitment to establish an MPA encompassing the entire Exclusive Economic Zone (EEZ) of 445,000 square kilometres, at the time making it the largest fully protected MPA in the Atlantic Ocean. This commitment sees commercial fishing and mineral extraction prohibited throughout the MPA, representing a significant step toward the conservation of marine biodiversity in the region. Ascension Island has a history of both subsistence fishing by the local community and offshore tuna fisheries, as well as the historic overexploitation and subsequent recovery of its green turtle population (Weber et al., 2014; Rowlands et al., 2019). Despite these human uses it has reportedly avoided the systematic declines of marine life seen in much of the world (Burns et al., 2020). Its remote location and small human population (ca. 800) have likely provided a buffer to some human impacts (Letessier et al., 2019) and the newly established MPA provides an opportunity to ensure that future declines are avoided.

We characterised pelagic wildlife assemblages across the Ascension Island EEZ through the analysis of baseline data collected prior to the establishment of the Ascension Island MPA in 2019. In particular we determined the association of pelagic assemblages with a variety of bathymetric and dynamic ocean features. We used mid-water stereo Baited Remote Underwater Video Systems (BRUVS) over the course of three expeditions to record pelagic wildlife, documenting patterns in diversity, abundance, biomass, size structure, and assemblage composition in waters associated with Ascension Island, three seamounts, apparent fronts, and random offshore areas within the EEZ.

\section{MATERIALS AND METHODS}

\section{Study Site}

Ascension Island is an isolated volcanic peak in the South Atlantic Ocean $\left(14^{\circ} 22^{\prime} \mathrm{W} 7^{\circ} 56^{\prime} \mathrm{S}\right)$, approximately $1,600 \mathrm{~km}$ from the coast of Africa, 2,250 km from the coast of Brazil and $90 \mathrm{~km}$ west of the Mid-Atlantic Ridge (Figure 1). The island rises $860 \mathrm{~m}$ above sea level and the base of the volcano covers approximately $2,000 \mathrm{~km}^{2}$ at a depth of 3,200 $\mathrm{m}$ (Ammon et al., 2009). The Ascension Island EEZ extends $200 \mathrm{~nm}$ from the island; it straddles the Mid-Atlantic Ridge and the associated volcanic activity has produced several subsurface features. There are three prominent seamounts situated within the EEZ. Grattan and Young seamounts, collectively known as the "southern seamounts" are located adjacent to the Mid-Atlantic Ridge 256 
and $315 \mathrm{~km}$ to the southeast of the island, rising to within 101 and $77 \mathrm{~m}$ of the surface, respectively, and separated by a deep $>3,000$ m channel (Weber et al., 2018). Harris Stewart Seamount lies $295 \mathrm{~km}$ to the west of Ascension Island and is a relatively flattopped feature with the majority of the summit plateau at around $500 \mathrm{~m}$ deep and several domed sub-peaks, the shallowest of which rises to within $265 \mathrm{~m}$ of the surface. Due to their extreme isolation, these features have remained little studied until recently (Weber et al., 2018). In the equatorial Atlantic, meridional convergence of the Atlantic South Equatorial Current (SEC) and the Guinea current, along with the seasonal formation of the Atlantic cold tongue generate oceanographic fronts (Giordani and Caniaux, 2014). This front formation is strongest at the northern boundary of the SEC, just north of the equator, however, frontal activity may occur on a smaller scale on the SEC's southern boundary leading to frontogenesis in the Ascension Island EEZ (Giordani and Caniaux, 2014).

\section{Video Collection and Processing}

We collected video footage using mid-water stereo-Baited Remote Underwater Video Systems (BRUVS). BRUVS were used as they provide standardised metrics on pelagic wildlife assemblages (Bouchet et al., 2018). The individual rig configuration and deployment of mid-water BRUVS were standardised across all expeditions (Bouchet et al., 2018). Each rig was baited with $1 \mathrm{~kg}$ of crushed tuna per deployment sourced as waste from a local fish processing facility. Rigs were deployed during daylight hours at a depth of $10 \mathrm{~m}$ for a minimum of $120 \mathrm{~min}$ and set in a longline formation of 5 rigs (hereon referred to as a "set") with each rig on a set separated by $200 \mathrm{~m}$ of line. Rigs were deployed in the epipelagic zone to sample the wide range of taxa present in this environment, allow sampling over shallow features and provide adequate natural light for identification of animals. Our sampling consisted of 655 deployments at 131 sites across 3 expeditions: January 2017, May/June 2017, and January 2018 (Figure 1). As sampling was carried out across the Ascension Island EEZ, not all features could be sampled in every survey. Sample sites were arranged radiating out along the cardinal directions (i.e., north, east, south, west) up to $40 \mathrm{~km}$ from the island and the summits of the southern seamounts into surrounding waters. At Harris Stewart Seamount only the east-west axis was sampled due to time restrictions. This $40 \mathrm{~km}$ limit was based on a maximum radius of influence reported in a meta-analysis of fisheries data from seamounts (Morato et al., 2010). During the 2018 expedition, we also sampled apparent front zones identified in near-real time by remote sensing data supplied by the NERC Earth Observation Data Acquisition and Analysis Service (NEODAAS) to investigate the effects of dynamic oceanic features on pelagic assemblages. Putative fronts were identified in daily, Level 3 AVHRR and MUR SST satellite data by compositing detections from the single-image edge detection (SIED) algorithm of Cayula and Cornillon (1992) over 3 and 7 day periods (see Miller et al., 2015 for details; thermal front detection threshold $=0.04^{\circ} \mathrm{C}$ ). BRUVS deployments were targeted to areas of high frontal density identified in the resulting composite maps. It should be noted that persistent cloud cover in this region affects the accuracy and timeliness of front detection; hence a delay of up to several days between cloud-free observation of a dynamic front and sampling caused some uncertainty in these locations. Post-sampling, we also used these remote sensing data averaged over a longer time period, using available monthly cloud-free observations from 2011 to 2018 to calculate metrics for each sample set characterising the thermal front conditions based on the methods of Miller et al. (2015). These metrics were: distance to the nearest major front (Fdist), defined as the distance to the closest major front, determined using a simplified version of the frontal strength map (in pixels); front gradient density (Fgrad), defined as the gradient magnitude of detected fronts, spatially smoothed to give a continuous distribution of frontal activity $\left({ }^{\circ} \mathrm{C} /\right.$ pixel distance; standard sigma $=20$ pixels $)$; and front persistence (Fpers), defined as the fraction of cloud-free observations of a pixel for which a front was detected, spatially smoothed to give a continuous distribution (standard sigma $=20$ pixels). We haphazardly sampled offshore sites throughout the EEZ to characterise the offshore pelagic community.

We processed the video footage to generate taxonomic identifications, relative abundance, and size. All video was processed using standard procedures with the software Event Measure $^{1}$ (Cappo et al., 2006). We identified each individual animal to the lowest possible taxonomic resolution, recorded the maximum number of each taxa in a single video frame $(\mathrm{MaxN})$ as our relative abundance measure, and estimated fork length based on photogrammetric measurements. Not all individuals of each taxa were measured on every deployment due to photogrammetric constraints. Therefore, to calculate mean lengths and biomass, we used the mean FL for measured individuals of each taxa and applied this mean to all individuals of that taxa for that deployment. Where measured lengths of animals were not available, we used the mean length of animals of the same taxa from the same set, site, or expedition. If no measurements were made for a given taxa, the common length reported in FishBase or SeaLifeBase was used. We calculated the mean weight in kilograms of each taxa using fork lengths and length-weight relationships from FishBase (Froese and Pauly, 2019) and SeaLifeBase (Palomares and Pauly, 2019). Biomass was then estimated as the product of the mean weight and abundance.

We calculated four univariate metrics from the BRUVS footage to allow us to quantify overall assemblage characteristics. Mean Taxonomic Richness (TR) was derived for each sample set by taking the sum of the total number of taxa observed on each deployment of the set and dividing by the number of deployments in that set. We calculated mean Total Abundance (TA) and mean Total Biomass (TB) by taking the sum of MaxNs for all species on all deployments of a set, or the sum of their weights, and dividing by the number of deployments on that set. Mean fork length (FL) was calculated by taking the sum of all lengths for all individuals of all taxa counted on a set and dividing by the total MaxN.

\section{Functional Group Designations}

We assigned taxa to functional groups to understand how their distribution, abundance, and size varied across the EEZ.

\footnotetext{
${ }^{1}$ www.seaGIS.com.au
} 


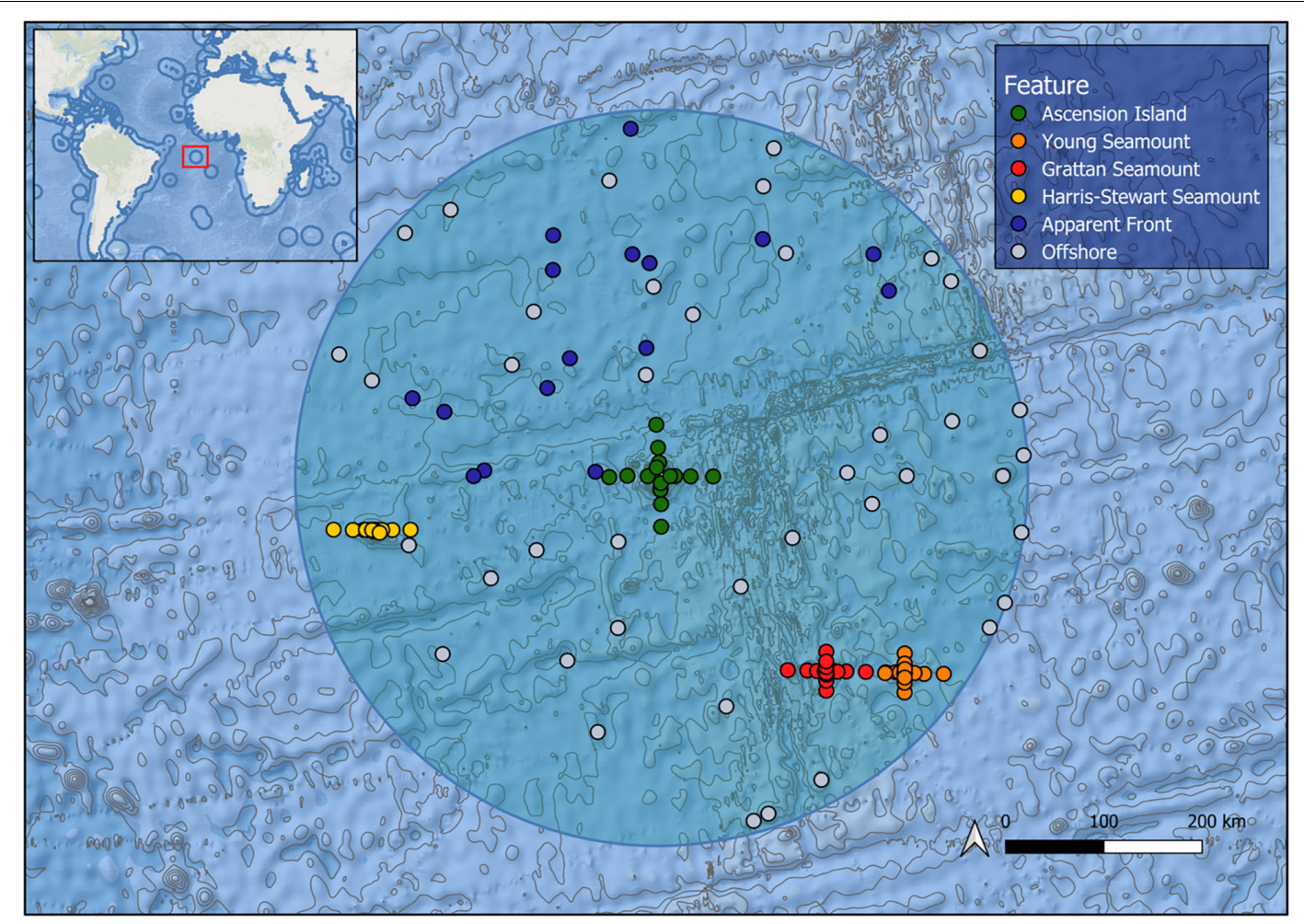

FIGURE 1 | Map of the Ascension Island EEZ (shaded circle) showing bathymetry and sampling effort by feature, each point represents a deployment of five mid-water BRUVS.

As taxonomic composition can be highly patchy in pelagic environments, grouping taxa by functional traits increases sample size and statistical power while retaining ecological relevance. Group designations were based on a combination of taxonomic classification, mean length, trophic level, and primary food source (Supplementary Table 1). All taxa with a mean length less than $25 \mathrm{~cm}$ were grouped as forage fishes; this included juvenile pelagic phases of coastal species such as flutemouths (Fistulariidae) and filefish (Monacanthidae), as well as forage fish such as scads (Decapterus sp.) and flying fish (Exocoetidae). Sharks were grouped together as were tunas. Blue marlin (Makaira nigricans) and sailfish (Istiophorus platypterus) were combined as billfishes. Large piscivores not already allocated to a category (i.e., sharks, tunas, or billfish) were grouped together based on size ( $>25 \mathrm{~cm}$ mean length), diet (piscivorous), and trophic level $(>4)$. The large non-piscivores group included all invertivorous and planktivorous fishes and rays over $25 \mathrm{~cm}$ and with a trophic level less than 4 ; this group included mobula rays, molas, and triggerfish. Dolphins and turtles were assigned their own groups. Remoras (Remora remora and Echeneis naucrates) were not included in functional group analyses as they were exclusively associated with sharks.

\section{Statistical Analyses}

We applied a range of statistical analyses to test the effect of bathymetric and dynamic features on the biological metrics we derived. We investigated patterns in overall diversity, abundance, size, and biomass distribution in relation to features. Features were defined as Ascension Island, Grattan Seamount, Young Seamount, Harris Stewart Seamount, apparent fronts, and offshore. We used Permutational Analyses of Variance (PERMANOVA) in PRIMER and PERMANOVA + software (Anderson, 2017) based on Euclidean distance resemblance matrices of $\log (\mathrm{x}+1)$ transformed data to test for differences among these features for the univariate metrics TR, TA, TB, and FL. A significance level of $\alpha=0.05$ was used throughout. We used PERMANOVAs based on Euclidean distance matrices of untransformed data, to test for univariate differences front metrics among features. We also used multivariate PERMANOVAs, based on Bray-Curtis resemblance matrices of square root transformed values to test for the effects of features on the composition of functional groups based on both abundance and biomass. Pairwise PERMANOVAs were subsequently used to determine where differences among features lay. A principal coordinate analysis plot (PCO) based on functional group abundance was used to identify the groups associated with the varying features.

\section{RESULTS}

We recorded a diverse range of wildlife on BRUVS deployed throughout the Ascension Island EEZ, including 3,860 individual pelagic fishes, marine mammals, and turtles representing 39 
taxa from 33 genera and 18 families. We identified $78 \%$ of individuals to species level, $12 \%$ to genera, and $8 \%$ to family, with $2 \%$ of individuals as unidentified juveniles (Supplementary Table 1). On average $1.61( \pm 0.11 \mathrm{SE})$ taxa were recorded per deployment. Length measurements were obtained for 2,159 individuals ranging from a $0.5 \mathrm{~cm}$ juvenile driftfish (Psenes sp.) to a $310.9 \mathrm{~cm}$ blue marlin (Makaira nigricans); the overall mean length was $36.1 \mathrm{~cm}$ ( $\pm 3.55 \mathrm{SE}$ ). Direct measurements were possible for individuals of each taxa on each deployment in $87.3 \%$ of cases, with measurements from the same set or same expedition used in 6.8 and $4.4 \%$ of cases, respectively. Lengths were derived from global BRUVS observations or from the common lengths reported on FishBase/SealifeBase for $2 \%$ of the observations. Sample sets varied substantially in TA and TB with a mean of $5.89( \pm 0.80 \mathrm{SE})$ individuals weighing $22.4 \mathrm{~kg}$ $( \pm 3.31 \mathrm{SE})$ recorded on each deployment. The most numerous individuals were forage fishes with 1,903 (49.3\%) records $(1,640$ records after remoras were removed), followed by large piscivores (712; 18.4\%), sharks $(687 ; 17.8 \%)$, tunas $(496 ; 12.8 \%)$, billfishes (26; $0.7 \%)$, dolphins $(15 ; 0.4 \%)$, turtles $(12 ; 0.3 \%)$, and large non-piscivores $(9 ; 0.2 \%)$.

Features varied significantly with respect to TR, TA, TB, and FL (Figure 2 and Supplementary Tables 2, 3). Ascension Island had a relatively high diversity and abundance of pelagic fauna with moderate sized animals $(33.0 \mathrm{~cm} \pm 8.60 \mathrm{SE})$ making up an intermediate level of biomass. Ascension Island had the second highest TR $(2.04 \pm 0.27)$ and TA $(9.58 \pm 2.37 \mathrm{SE})$, significantly higher than those at Harris Stewart, apparent fronts, and offshore sites, with TA also higher than at Young Seamount. TB and FL at Ascension Island were moderate and significantly higher than at offshore sites. The southern seamounts of Grattan and Young were generally similar to one another, being characterised by large animals and high biomass as well as high diversity and relatively high abundance. Both seamounts had higher FL $(64.9 \mathrm{~cm} \pm 11.98 \mathrm{SE}$ and $54.4 \mathrm{~cm} \pm 8.56 \mathrm{SE}$ at Young and Grattan Seamounts, respectively) and TB (168 kg \pm 62.4 SE and $107 \mathrm{~kg} \pm 39.5 \mathrm{SE}$ at Grattan and Young Seamounts, respectively) than at offshore sites $(15.6 \mathrm{~cm} \pm 4.42 \mathrm{SE} ; 8.5 \mathrm{~kg} \pm 2.34 \mathrm{SE})$. Grattan was also higher in TB than at apparent fronts and higher in TR $(2.21 \pm 0.46 \mathrm{SE}$ species $)$ and TA $(10.2 \pm 3.55 \mathrm{SE})$ than Harris Stewart Seamount $(1.18 \pm 0.32$ SE species; $2.33 \pm 1.01$ $\mathrm{SE})$. Harris Stewart Seamount had relatively low values across all metrics compared to the other bathymetric features, having very few animals which were of a moderate size. It only differed from offshore sites in having significantly larger FL (41.7 $\pm 9.55 \mathrm{SE})$ and lower TA $(2.33 \pm 1.01 \mathrm{SE})$. Apparent fronts and offshore sites did not significantly differ in any univariate metrics, however, apparent fronts had a TB $(17.0 \mathrm{~kg} \pm 7.80 \mathrm{SE})$ twice as high as that at offshore sites and TA and FL were also slightly higher at fronts. Apparent fronts were also much more variable leading to differing results in pairwise comparisons with other features. As such, apparent fronts did not differ significantly from the feature with the highest value for TR, TA, and FL.

Functional assemblage composition varied significantly among features, both in terms of abundance (Pseudo-F $d f=$ ${ }_{5}=4.47, p=0.001$; Figure 3A ) and biomass (Pseudo-F $d f=$ ${ }_{5}=2.28, p=0.002$; Figure 3B and Supplementary Tables 2-4).
Overall, the pelagic assemblage at Ascension Island had a distinct and diverse functional composition. Ascension Island was the only location at which turtles were recorded, and the primary location for dolphins and large non-piscivores. It had a moderate complement of large predators with 66 and $40 \%$ of combined teleost and elasmobranch predators by biomass and abundance, respectively, and forage fishes made up the majority by abundance. This composition was significantly different to all other features by biomass and all but apparent fronts by abundance. The southern seamounts had very high biomass and abundance of all the large pelagic predator groups, with combined sharks, tunas, large piscivores, and billfish forming $>99.9$ and $>86 \%$ of the assemblage by biomass and abundance, respectively. Overall predator abundance and biomass was generally lower at Harris Stewart Seamount, apparent fronts, and offshore sites with forage fishes making up a larger proportion of the abundance; within this group, however, predator abundance was higher at apparent fronts than at offshore sites and Harris Stewart Seamount. Harris Stewart and offshore sites also differed significantly in their functional composition of abundance with proportionally more sharks and large piscivores at Harris Stewart and more forage fishes at offshore sites. There was no significant difference in functional composition of the assemblages among the three seamounts and apparent fronts. All three seamounts also differed from offshore sites in their functional composition by abundance and the southern seamounts and apparent fronts differed from offshore sites in their functional composition by biomass. Offshore sites were characterised by high relative abundances of forage fishes with very few predators, however, the predators present contributed most of the biomass. Sharks were particularly prevalent at the southern seamounts being 3.25-5.18 times more abundant and weighing 2.52-3.12 times more than the next most shark dense location (Ascension Island). Billfishes were found in similar abundances across Ascension Island and the southern seamounts. Tunas were particularly prevalent at Grattan Seamount with high abundances of skipjack and yellowfin tuna at sites close to the summit driving this pattern. Tunas were observed in relatively lower abundances at apparent fronts, Young Seamount, and Ascension Island. Large piscivores were found in similar biomass at Ascension Island and the southern seamounts, however, abundance was higher at Ascension Island indicating higher numbers of smaller individuals. Dolphins were observed only at Ascension Island and Harris Stewart Seamount. Forage fishes were observed at all locations but in varying proportions. They contributed more than half of the assemblage by abundance at all locations except the southern seamounts, reaching 92\% of all animals at offshore sites, and contributing only $13 \%$ of the individuals at both the southern seamounts. These patterns are visualised in the PCO which indicates high abundances of sharks, large piscivores, and tunas predominantly at the southern seamounts along with some Ascension Island and apparent front sites (Figure 4). It also indicates high abundances of forage fishes at offshore and Ascension Island locations as well as some apparent front sites. The lower right quadrant of the plot was relatively clear, indicating that sites either exhibited high predator abundance or high abundance of forage fishes but not 

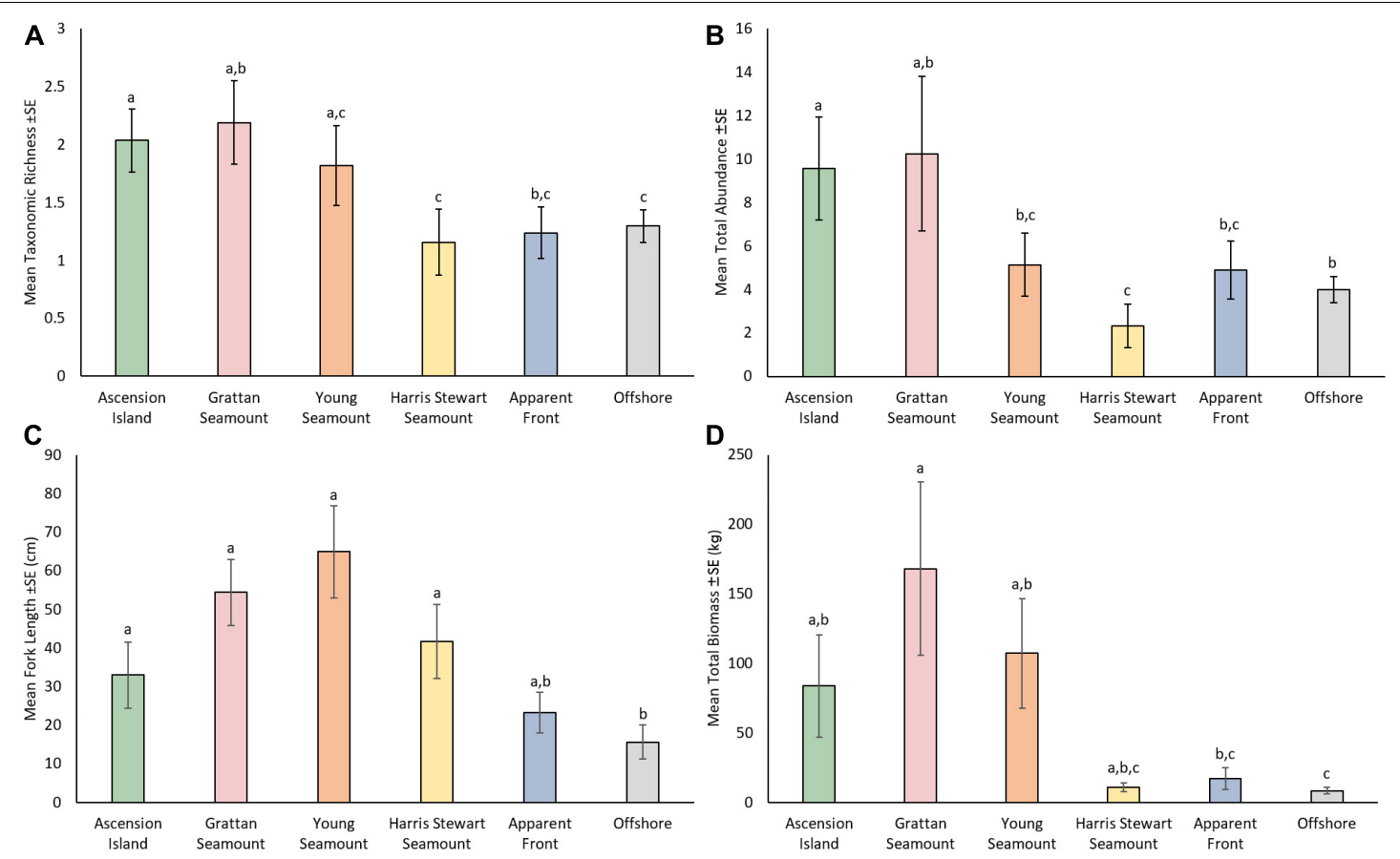

FIGURE 2 | Mean taxonomic richness (A), mean total abundance (B), mean fork length (C), and mean total biomass (D) by feature for all pelagic animals observed on all mid-water BRUVS deployments from Ascension waters in 2017/2018. Shared letters indicate no significant difference ( $p>0.05)$ based on results of pairwise comparisons from PERMANOVAs based on Euclidean distance matrices of $\log (x+1)$ transformed data with 999 permutations. Error bars indicate one standard error.

both. Billfishes, large non-piscivores, dolphins, and turtles were observed in lower numbers and therefore had a lower impact on assemblage metrics.

Features varied significantly in their thermal front metrics (Supplementary Tables 5 and 6), apparent fronts had the highest mean Fgrad $(0.031 \pm 0.004$ SE), which was significantly higher than all bathymetric features and was higher than, although marginally not significantly different to offshore sites $(p=0.067 ; 0.022 \pm 0.002)$. Apparent fronts had the highest Fpers $(0.024 \pm 0.003)$, which was significantly higher than the three seamounts. Fpers at apparent fronts, however, was not significantly different from that at Ascension Island ( $p=0.188$; $0.018 \pm 0.003 \mathrm{SE})$ or offshore sites $(p=0.684 ; 0.022 \pm 0.003$ $\mathrm{SE})$. Mean Fdist at apparent fronts was $10.25 \mathrm{~km}( \pm 1.97 \mathrm{SE})$ which was closer than all features except for Young Seamount $(7.98 \mathrm{~km} \pm 1.62 \mathrm{SE})$, and significantly lower than at Ascension Island $(p=0.015 ; 19.14 \mathrm{~km} \pm 2.86 \mathrm{SE})$ and Harris Stewart Seamount $(p=0.001 ; 26.65 \pm 3.57 \mathrm{SE})$.

\section{DISCUSSION}

We found that the bathymetric and dynamic features in the Ascension Island EEZ have a significant influence on the distribution, diversity, abundance, size, biomass, and functional composition of pelagic wildlife assemblages within the territory. We also show that these effects vary both among and within feature types with environmental conditions influencing assemblage composition. Our results demonstrate that pelagic wildlife within the EEZ is primarily concentrated around the shallow bathymetric features of Ascension Island, and the Grattan and Young Seamounts which had the most biodiverse assemblages with the highest biomass. Dynamic features and the deeper seamount still had some influence on pelagic assemblages but did not aggregate animals at the same level. The establishment of the Ascension Island MPA, encompassing the entire EEZ, means that each of these features with its different complement of species is protected.

At Ascension Island, we observed a distinct pelagic assemblage characterised by a broad range of functional groups. Ascension Island is the only above-surface feature in the EEZ and is $1,600 \mathrm{~km}$ from the nearest land mass, thus representing the only coastal habitat in the region. Islands are often biological hotspots in relatively depauperate ocean basins, with several mechanisms suggested for their effect on marine communities. Upwelling, surface runoff, and capture of nutrients by benthic organisms are some of the suggested mechanisms driving higher productivity around islands and supplying the basal energetic requirements to sustain higher trophic levels (Doty and Oguri, 1956; Gove et al., 2016). These processes may be sustaining the pelagic predators we observed at Ascension Island with billfish recorded at their equal highest abundance at Ascension Island, and sharks and tunas found in moderate abundances. Large piscivores made up a greater proportion of the assemblage at Ascension Island than at the southern seamounts by abundance but not by biomass, tending to be smaller and more numerous. This finding in combination with the high abundance of pelagic juveniles suggests that the shallow waters of Ascension Island 
$\mathrm{p}$
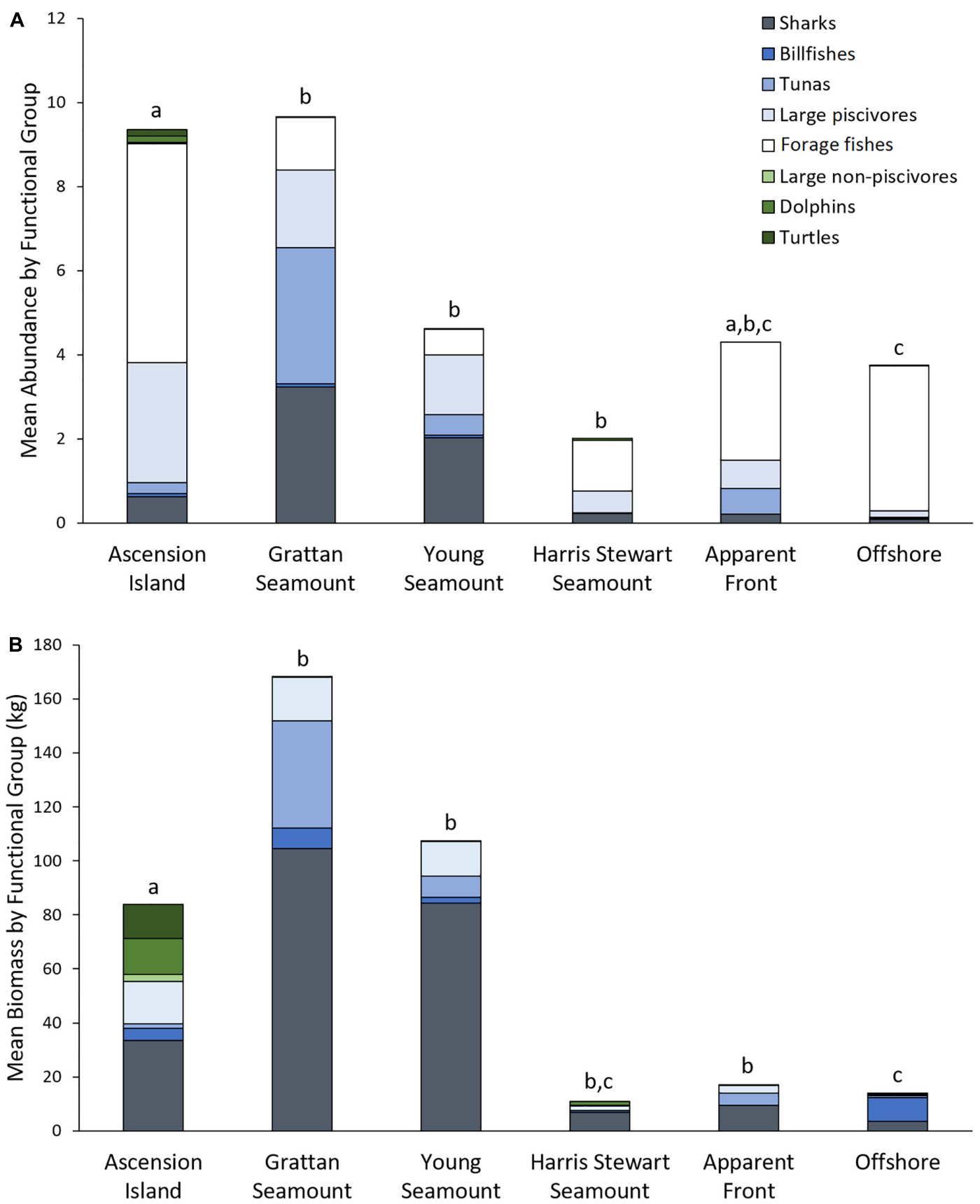

FIGURE 3 | Mean total abundance (A) and mean total biomass (B) for functional groups observed per set of mid-water BRUVS deployed at each of the features sampled within the Ascension Island EEZ. Letters indicate pairwise comparisons of PERMANOVAs based on Bray-Curtis resemblance matrices of square root transformed Total Abundance and Total Biomass data by functional group. Shared letters indicate no significant difference in functional composition ( $p>0.05)$.

may be important in the early life histories of both large piscivores and coastal species (Gillanders et al., 2003), and/or that the complement of large piscivore species differ among features and smaller species are found at Ascension Island. The high abundance of juvenile pelagic phases of coastal species we observed near Ascension Island could be due to the proximity to adult populations or also through active movement of juveniles toward structure as seen in other species (Montgomery et al., 2006). Forage fishes may also be more abundant near the island simply due to increased productivity (Gove et al., 2016). Coastal structure and dry land are also vital for certain species and provide a range of services. For example, the beaches of Ascension Island are home to the largest green turtle rookery in the South Atlantic (Weber et al., 2014), explaining our 


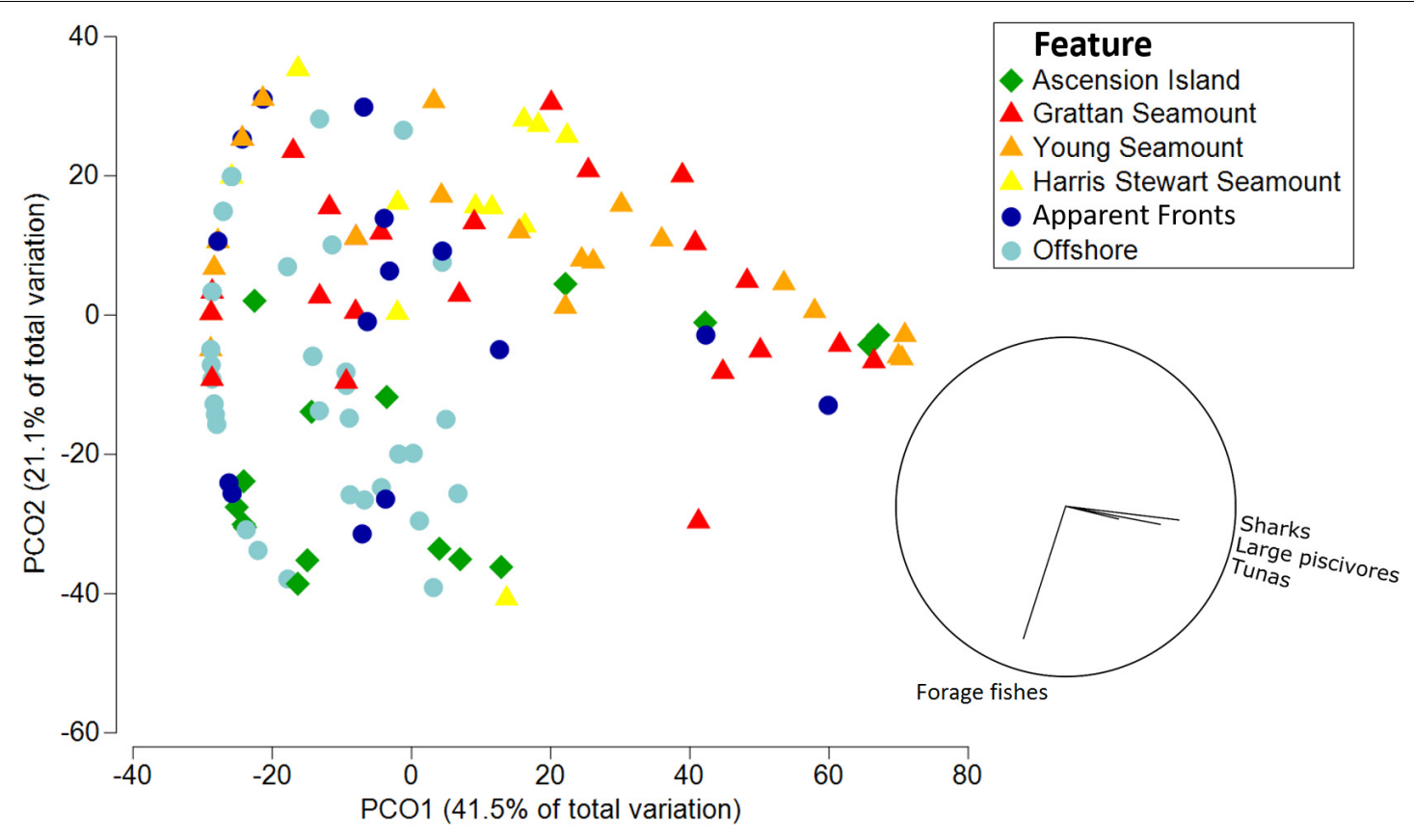

FIGURE 4 | Principal Components Analysis of total abundance of pelagic wildlife by functional groups. Symbols indicate the feature of the sample site, vector plot indicates functional groups with a correlation greater than 0.20 .

records of this species at the island and not elsewhere in the EEZ. Bottlenose dolphins (Tursiops truncatus) were also only recorded at Ascension Island, they were the primary drivers of dolphin abundance and biomass in our survey and are a coastal species previously observed at Ascension Island (Perrin, 1985). The relatively high biomass of large-non-piscivores at Ascension Island was driven by records of giant devil rays (Mobula mobular) which are known to frequent oceanic islands; the underlying relationship of this species with oceanic islands is not well understood, however, other Mobulid species are known to utilise shallow waters to access cleaning stations and to forage (Jaine et al., 2012), so Ascension's coastal waters may provide these services to giant devil rays too. The land mass of Ascension Island may also alter the environmental characteristics of the surrounding waters, providing a sheltering effect and access to shallow structure which likely would alter the niches available to pelagic species and therefore help to explain the differences observed.

The seamounts within Ascension's EEZ differed significantly in their effect on pelagic wildlife with the southern seamounts being quite similar in their assemblage, which was more diverse, and of greater abundance and biomass than that at Harris Stewart Seamount. The southern seamounts harboured assemblages dominated by large predators. Sharks were prevalent at these locations and tunas, billfish, and large piscivores were also relatively plentiful. This finding is consistent with Morato et al. (2010) that demonstrated increased biodiversity of commercial species around seamounts. The relatively shallow summits of the southern seamounts were likely the major factor in driving the aggregations we observed. Shallow summits allow pelagic predators to forage on demersal species without leaving the photic zone and with reduced thermal constraints (Andrzejaczek et al., 2018, 2019). Tunas associated with oceanic islands and seamounts elsewhere in the South Atlantic have been found to forage on coastal species (e.g., butterfly fish) at high rates (Laptikhovsky et al., 2020) indicating that the demersal assemblages at these physical structures are an important source of prey. The observation of low abundances of juvenile and small pelagic fish at the southern seamounts may either be due to depletion by the high abundance of large predatory species or avoidance of these features to inhabit areas with lower predation risk. Shallow features also promote dynamic oceanographic processes which increased upwelling and mixing (Lueck, 1997; Hosegood et al., 2019). Mixing can increase oxygen availability (Van Haren et al., 2017) and productivity (Bissett et al., 1994). Therefore, these shallow seamounts boast a range of benefits to pelagic predator populations.

Harris Stewart Seamount did not have the same bioaggregating effect as the other physical features: it possessed a comparatively depauperate pelagic community. For seamounts, the summit depth has a large impact on productivity and this is likely a major factor in our finding (Morato et al., 2008). At $265 \mathrm{~m}$, the shallowest point at Harris Stewart Seamount is more than double the minimum depth at the southern seamounts. The geomorphology of Harris Stewart is also very different to that of the southern seamounts. It is a much flatter topped feature with an expansive plateau at approximately $500 \mathrm{~m}$ and several domed sub-peaks (Weber et al., 2018). It therefore may have a more complex association with marine life and although there were not substantial epipelagic populations present in our 
surveys at Harris Stewart Seamount, this does not rule out its possible use by deeper water meso-pelagic species such as bigeye tuna and swordfish (Holland et al., 1999). Deep-water surveys have highlighted rich benthic communities at each of the physical features we sampled, including Harris Stewart Seamount (Barnes et al., 2019), studies of tunas in the region indicate that seamounts are important feeding grounds, and stomach content analyses show that, in addition to pelagic prey, they also feed on demersal species (Laptikhovsky et al., 2020). Although the pelagic community at Harris Stewart Seamount was not as rich as those at the southern seamounts, there were some indications that it may have some influence on the pelagic assemblage above it. The functional composition by abundance at Harris Stewart Seamount was different to that at offshore sites and more similar to the other seamounts. It was also the only site at which an oceanic whitetip shark (Carcharhinus longimanus) was recorded, and the only offshore location where dolphins were observed. Further sampling, perhaps targeting the sub-peaks not sampled in this survey, and in particular targeting deeper swimming species may help to illuminate the effect that Harris Stewart has on pelagic species.

The effect of fronts on pelagic assemblages at Ascension Island warrants further investigation. We did not observe any statistically significant differences in univariate metrics between apparent fronts sites and offshore sites. However, the functional composition of the pelagic assemblage at apparent fronts was more similar to that of the seamounts sampled than offshore sites. Additionally, although not statistically significant, biomass at apparent fronts was double that of offshore sites and mean fork length and mean abundance were also higher. Some pelagic species such as blue sharks and tunas are known to be strongly associated with frontal features (Queiroz et al., 2012; Xu et al., 2017). Our PCO indicated that, while most offshore and apparent front sites had a similar composition of abundance, two apparent front sites were associated with relatively high abundances of sharks, large piscivores, and tunas, comparable to sites at the southern seamounts. This was not the case for random offshore locations which all had relatively low abundances of these groups. That some apparent front sites had high predator abundances and some did not indicates that either certain frontal features are more important to pelagic wildlife than others, that these features have a patchy distribution of pelagic wildlife which is not always captured in sampling efforts, or that only some of the deployments at apparent fronts accurately sampled fronts. The latency between receiving satellite data and generating front maps meant that the locations sampled were based on locations of putative thermal fronts 1-2 days previously, which will have resulted in some spatial mismatch if fronts were dynamic or ephemeral. The satellite limitations due to cloud cover would also cause some degradation to the accuracy of front metrics. Although differences were not statistically significant, apparent fronts had higher frontal activity than offshore sites, suggesting we had some success in our targeted sampling. The sampling of frontal features by chance at other features and offshore sites could have reduced the clarity of differences both in front metrics and biological metrics between these features and fronts. For example, Young seamount had the lowest mean distance to front but lower front gradient density and front persistence than apparent fronts suggesting that perhaps a weak or ephemeral front was present over the feature at the time of sampling. Apparent front sites were always within $27 \mathrm{~km}$ of a front site with a mean of $10.25 \mathrm{~km}$ ( $\pm 1.97 \mathrm{SE}$ ), however, our results suggest that perhaps these features need to be sampled at an even more localised scale. The apparent front site which stood out most on the PCO as being associated with high abundances of pelagic predators was the apparent front site which had the lowest distance to front of any site we sampled. This site was on average $2.42 \mathrm{~km}$ from the nearest major front, indicating that front effects may only occur in a limited range around the feature. Oceanic fronts are dynamic and rapidly changing features, both spatially and temporally, and are therefore difficult to sample (Budillon and Rintoul, 2003). Additionally, while the Ascension Island EEZ may have some frontal activity, this activity is likely more patchy and ephemeral than at larger frontal features such as those to the north of the South Equatorial Current (Giordani and Caniaux, 2014). Ground-truthing with in situ sampling may help to further determine the effectiveness of our front sampling and therefore the effects of front zones on pelagic communities in the Ascension Island EEZ. Species specific investigations may also allow us to tease apart these associations and determine whether any species of particular conservation concern utilise these features often.

The offshore locations sampled were generally depauperate, with most of the animals recorded being forage fishes. With the lack of significant mixing or frontal action offshore waters are generally oligotrophic and host lower abundances of pelagic wildlife (Gove et al., 2016). Offshore waters are however an important habitat in the early life history of many species, with $90 \%$ of marine fishes having a pelagic larval stage (Bonhomme and Planes, 2000). Several mechanisms are suggested for sustaining this life history strategy (Bonhomme and Planes, 2000), and increased survival due to low predator abundances in the offshore environment is likely a contributing factor. Our results conform to this general pattern with many small fish and few predators. The few predators present could be targeting the forage fishes in this environment or transiting between higher productivity features. It should also be noted that BRUVS surveys, although effective in sampling a broad range of species, only sampled the shallow, epipelagic zone, and during the daytime when many pelagic species migrate into deeper waters (Lerner et al., 2012; Thygesen et al., 2016). This likely limits our ability to detect deeper-schooling and vertically migrating species in offshore areas. Noting that former commercial fishing activity in the Ascension EEZ occurred in offshore areas and at depths $>100 \mathrm{~m}$, offshore waters may harbour assemblages not captured in this study located deeper in the water column.

The implementation of a no-take MPA at Ascension Island EEZ, encompasses a range of features with different complements of pelagic species, several of which are of significant conservation concern. Many of the large bodied species we observed are under substantial pressure from commercial fishing and other impacts globally (Collette B.B. et al., 2011; Juan-Jordá et al., 2011; Dulvy et al., 2014; Roff et al., 2018), and several are classified as threatened under the IUCN Red List criteria. We observed a broad range of threatened species across the territory, for 
example we recorded Near Threatened blue sharks (Prionace glauca; Rigby et al., 2019a) at apparent fronts, Vulnerable silky sharks (Carcharhinus falciformis; Rigby et al., 2017) and blue marlin (Makaira nigricans; Collette et al., 2011) at the southern seamounts, Endangered giant devil rays (Mobula mobular; Marshall et al., 2019) and green turtles (Chelonia mydas; Seminoff, 2004) at Ascension Island, and a Critically Endangered oceanic whitetip shark (Carcharhinus longimanus; Rigby et al., 2019b) at Harris Stewart Seamount. The waters of the Ascension Island EEZ have long been remarked upon for their exceptional abundance of marine wildlife and have reportedly avoided the steep systematic declines in wildlife observed in much of the world's oceans (Burns et al., 2020). Our results support this view showing high abundance and biomass of many species threatened in other parts of their range. We show that the different features within the territory harbour significantly different pelagic assemblages, all of which include species of significant conservation concern, therefore monitoring efforts should encompass each of these environments.

We recorded high concentrations of large predators throughout our survey and at the southern seamounts in particular. The high value and conservative life history strategy of many pelagic predators make them particularly vulnerable to overexploitation (Collette B.B. et al., 2011). Remnant populations of large predators are of particular conservation concern given the global scale removal of this group from our oceans (Worm and Tittensor, 2011). Large mature individuals also contribute disproportionately to reproduction (Barneche et al., 2018) and therefore the protection of these individuals will contribute proportionally more to conservation efforts. The southern seamounts therefore represent a particularly valuable conservation opportunity which may be able to contribute substantially to the populations of these predator species within the region.

The establishment of the Ascension Island MPA presents a substantial conservation opportunity, however effective management and enforcement is vital to the effectiveness of marine reserves (Guidetti et al., 2008) and the surveillance and enforcement of large MPAs can be challenging (Wilhelm et al., 2014). Recent developments in the monitoring and surveillance of fishing vessels such as the methods applied by Global Fishing Watch ${ }^{2}$ increase the capacity to detect possible illegal activity and respond with enforcement measures accordingly. Previous fishing in the region and the presence of fishing vessels close to the EEZ boundary indicate that Ascension Island's EEZ is a desirable fishing location and that adequate enforcement is necessary to ensure Illegal Unreported and Unregulated (IUU) fishing is kept under-control (Rowlands et al., 2019). Seamount communities can be decimated quickly by overfishing, and the removal of species with high residency may cause localised extinction (Luiz and Edwards, 2011). Therefore, illegal fishing could have a disproportionate impact on the assemblages of commercially valuable predators we observed at the southern seamounts. Additionally, legal extractive activities such as subsistence and recreational fishing, which has been

${ }^{2}$ www.globalfishingwatch.org highlighted as a tourism opportunity at Ascension Island (La Bianca et al., 2018), may still have substantial impacts on fish populations (Cooke and Cowx, 2004), often targeting large bodied predators as trophy fishes (Lewin et al., 2006), and therefore disproportionately impacting populations of concern (Coleman et al., 2004). Potential impacts of these activities should therefore be closely monitored, and enforcement measures put in place to ensure effective management and the success of the MPA.

The recently established MPA at Ascension Island encompasses several important environments harbouring diverse and important pelagic assemblages. Our work provides a baseline description of the pelagic fauna present against which any future changes can be compared. MPAs and their effective management are an important tool in halting and reversing declines in global populations of marine species. Game et al. (2009) called for increased protection of the pelagic environment and suggested that protecting representative examples of all pelagic habitats is needed. Our work at Ascension Island supports this approach strongly, illustrating that various physical and oceanographic features in the pelagic environment have different functional assemblages and contribute collaboratively to biodiversity. The Ascension Island MPA incorporates several of these features, increasing the biodiversity it conserves and serving as an examplar to marine conservation efforts elsewhere in the global ocean. It also illustrates that targeting seamounts in combination with oceanic islands may be a particularly effective way to conserve large bodied and vulnerable pelagic predators as well as other functional groups, maximising biodiversity protection. The abundant populations of threatened species at Ascension Island also indicates that although human impacts now span the global ocean (Halpern et al., 2008; Tickler et al., 2018) remote regions where these effects are buffered may still hold relatively intact assemblages which can be protected before these pressures deplete them further (Juhel et al., 2017; Letessier et al., 2019). There is a growing body of evidence that large marine reserves confer conservation and fisheries benefits even for highly mobile pelagic predators like those we recorded (Boerder et al., 2017). The work we present here supplies important baseline information of pelagic wildlife assemblages throughout the EEZ which can be compared with future values collected using the same standardised sampling techniques. Through time this will provide a consistent measure which will allow the effects of protection to be observed not only in abundance and diversity of species present, but also in their size and biomass. The establishment of this large marine reserve represents a substantial move forward in marine conservation in the Atlantic and it is therefore imperative that the effective management, enforcement and success of this reserve serve as an example.

\section{DATA AVAILABILITY STATEMENT}

The raw data supporting the conclusions of this article will be made available by the authors, without undue reservation. 


\section{ETHICS STATEMENT}

The animal study was reviewed and approved by the University of Western Australia Animal Ethics Committee.

\section{AUTHOR CONTRIBUTIONS}

CT assisted in data collection, processed the video footage, analysed the data, and drafted the manuscript. JM provided guidance in statistical analyses and input into drafting the manuscript. SW, with assistance from JB and AR, developed the sampling design and carried out sampling efforts. PM derived front metrics necessary for statistical analyses. All authors participated in the editing and final preparation of the manuscript.

\section{FUNDING}

This work was co-funded by Her Majesty's Government, the Darwin Initiative (grant no. DPLUS063), the European

\section{REFERENCES}

Ammon, K., Dunai, T. J., Stuart, F. M., Meriaux, A. S., and Gayer, E. (2009). Cosmogenic $3 \mathrm{He}$ exposure ages and geochemistry of basalts from Ascension Island. Atlantic Ocean Quat. Geochronol. 4, 525-532. doi: 10.1016/j.quageo. 2009.09.003

Anderson, M. J. (2017). Permutational multivariate analysis of variance (PERMANOVA). In Wiley StatsRef: Statistics Reference Online, 1-15. doi: 10. 1002/9781118445112.stat07841

Andrzejaczek, S., Gleiss, A. C., Jordan, L. K. B., Pattiaratchi, C. B., Howey, L. A., Brooks, E. J., et al. (2018). Temperature and the vertical movements of oceanic whitetip sharks, Carcharhinus longimanus. Sci. Rep. 8, 1-12. doi: 10.1038/ s41598-018-26485-3

Andrzejaczek, S., Gleiss, A. C., Pattiaratchi, C. B., and Meekan, M. G. (2019). Patterns and drivers of vertical movements of the large fishes of the epipelagic. Rev. Fish Biol. Fish. 29, 335-354. doi: 10.1007/s11160-019-09555-1

Angel, M. V. (1993). Biodiversity of the Pelagic Ocean. Conserv. Biol. 7, 760-772. doi: 10.1046/j.1523-1739.1993.740760.x

Barneche, D. R., Robertson, D. R., White, C. R., and Marshall, D. J. (2018). Fish reproductive-energy output increases disproportionately with body size. Science 360, 642-645. doi: 10.1126/science.aao6868

Barnes, D. K. A., Sands, C. J., Richardson, A., and Smith, N. (2019). Extremes in benthic ecosystem services; blue carbon natural capital shallower than $1000 \mathrm{~m}$ in Isolated, Small, and Young Ascension Island's EEZ. Front. Mar. Sci. 6:663. doi: 10.3389/fmars.2019.00663

Benoit-Bird, K. J., Waluk, C. M., and Ryan, J. P. (2019). Forage species swarm in response to coastal upwelling. Geophys. Res. Lett. 46, 1537-1546. doi: 10.1029/ 2018GL081603

Bissett, W. P., Meyers, M. B., Walsh, J. J., and Muller-Karger, F. E. (1994). The effects of temporal variability of mixed layer depth on primary productivity around Bermuda. J. Geophys. Res. 99, 7539-7553. doi: 10.1029/93JC03154

Boerder, K., Bryndum-Buchholz, A., and Worm, B. (2017). Interactions of tuna fisheries with the Galápagos marine reserve. Mar. Ecol. Prog. Ser. 585, 1-15. doi: 10.3354/meps12399

Bonhomme, F., and Planes, S. (2000). Some evolutionary arguments about what maintains the pelagic interval in reef fishes. Environ. Biol. Fishes 59, 365-383. doi: 10.1023/A:1026508715631

Bouchet, P., Meeuwig, J., Huveneers, C., Langlois, T., Lowry, M., Rees, M., et al. (2018). "Marine sampling field manual for pelagic stereo-BRUVS (Baited Remote Underwater Videos)," in Field Manuals for Marine Sampling to Monitor
Union's BEST initiative (grant no. 1599), and National Geographic Pristine Seas.

\section{ACKNOWLEDGMENTS}

We would like to thank the captains and crews of the RRS James Clark Ross and the St Helena fishing vessel Extractor for their hard work in the field to make sampling on such a scale possible. We would also like to thank all researchers involved in the cruises, the NERC Earth Observation Data Acquisition and Analysis Service (NEODAAS) for nearreal time satellite support of the cruises, and the Marine Futures Lab technicians for their assistance in fieldwork and video processing.

\section{SUPPLEMENTARY MATERIAL}

The Supplementary Material for this article can be found online at: https://www.frontiersin.org/articles/10.3389/fmars. 2021.634599/full\#supplementary-material

Australian Waters, eds R. Przeslawski and S. Foster National (Canberra, ACT: Environmental Science Programme (NESP)).

Bouchet, P. J., Letessier, T. B., Caley, M. J., Nichol, S. L., Hemmi, J. M., and Meeuwig, J. J. (2020). Submerged carbonate banks aggregate pelagic megafauna in offshore tropical Australia. Front. Mar. Sci. 7:530. doi: 10.3389/fmars.2020. 00530

Bouchet, P. J., Meeuwig, J. J., Salgado Kent, C. P., Letessier, T. B., and Jenner, C. K. (2015). Topographic determinants of mobile vertebrate predator hotspots: current knowledge and future directions. Biol. Rev. 90, 699-728. doi: 10.1111/ brv. 12130

Braun, C. D., Gaube, P., Sinclair-Taylor, T. H., Skomal, G. B., and Thorrold, S. R. (2019). Mesoscale eddies release pelagic sharks from thermal constraints to foraging in the ocean twilight zone. Proc. Natl. Acad. Sci. U.S.A. 116, 17187-17192. doi: 10.1073/pnas.1903067116

Budillon, G., and Rintoul, S. R. (2003). Fronts and upper ocean thermal variability south of New Zealand. Antarct. Sci. 15, 141-152. doi: 10.1017/ S0954102003001135

Burns, P., Hawkins, J., and Roberts, C. (2020). Reconstructing the history of ocean wildlife around Ascension Island. Aquat. Conserv. Mar. Freshw. Ecosyst. 30, 1220-1237. doi: 10.1002/aqc.3304

Cabral, R. B., Bradley, D., Mayorga, J., Goodell, W., Friedlander, A. M., Sala, E., et al. (2020). A global network of marine protected areas for food. Proc. Natl. Acad. Sci. U.S.A. 117, 28134-28139. doi: 10.1073/pnas.2000174117

Cappo, M., Harvey, E., and Shortis, M. (2006). Counting and measuring fish with baited video techniques -an overview. Austr. Soc. Fish Biol. Works. Proc. 1, 101-114.

Cayula, J.-F., and Cornillon, P. (1992). Edge detection algorithm for SST images. J. Atmos. Oceanic Technol. 9, 67-80. doi: 10.1175/1520-04261992009<0067: EDAFSI $<2.0 . \mathrm{CO} ; 2$

Clarke, C., Lea, J. S. E., and Ormond, R. F. G. (2011). Reef-use and residency patterns of a baited population of silky sharks, Carcharhinus falciformis, in the Red Sea. Mar. Freshw. Res. 62, 668-675. doi: 10.1071/MF 10171

Coleman, F. C., Figueira, W. F., Ueland, J. S., and Crowder, L. B. (2004). The impact of United States recreational fisheries on marine fish populations. Science 305, 1958-1960. doi: 10.1126/science.1100397

Collette, B., Acero, A., Amorim, A. F., Boustany, A., Canales Ramirez, C., Cardenas, G., et al. (2011). Makaira nigricans. IUCN Red List Threat. Species 2011:e.T170314A6743776. doi: 10.2305/IUCN.UK.2011-2.RLTS. T170314A6743776.en 
Collette, B. B., Carpenter, K. E., Polidoro, B. A., Juan-Jordá, M. J., Boustany, A., Die, D. J., et al. (2011). High value and long Life-Double jeopardy for tunas and billfishes. Science 333, 291-292. doi: 10.1126/science. 1208730

Cooke, S. J., and Cowx, I. G. (2004). The role of recreational fishing in global fish crises. Bioscience 54, 857-859.

Di Lorenzo, M., Guidetti, P., Di Franco, A., Calò, A., and Claudet, J. (2020). Assessing spillover from marine protected areas and its drivers: a metaanalytical approach. Fish Fish. 21, 906-915. doi: 10.1111/faf.12469

Doty, M. S., and Oguri, M. (1956). The island mass effect. ICES J. Mar. Sci. 22, 33-37. doi: 10.1093/icesjms/22.1.33

Dulvy, N. K., Fowler, S. L., Musick, J. A., Cavanagh, R. D., Kyne, P. M., Harrison, L. R., et al. (2014). Extinction risk and conservation of the world's sharks and rays. eLife 3, 1-34. doi: 10.7554/elife.00590

Froese, R., and Pauly, D. (2019). FishBase. Available online at: www.fishbase.org. (accessed October 1, 2019)

Game, E. T., Grantham, H. S., Hobday, A. J., Pressey, R. L., Lombard, A. T., Beckley, L. E., et al. (2009). Pelagic protected areas: the missing dimension in ocean conservation. Trends Ecol. Evol. 24, 360-369. doi: 10.1016/j.tree.2009.01.011

Gillanders, B. M., Able, K. W., Brown, J. A., Eggleston, D. B., and Sheridan, P. F. (2003). Evidence of connectivity between juvenile and adult habitats for mobile marine fauna: an important component of nurseries. Mar. Ecol. Prog. Ser. 247, 281-295.

Giordani, H., and Caniaux, G. (2014). Lagrangian sources of frontogenesis in the equatorial Atlantic front. Clim. Dyn. 43, 3147-3162. doi: 10.1007/s00382-0142293-3

Gove, J. M., McManus, M. A., Neuheimer, A. B., Polovina, J. J., Drazen, J. C., Smith, C. R., et al. (2016). Near-island biological hotspots in barren ocean basins. Nat. Commun. 7, 1-8. doi: 10.1038/ncomms10581

Guidetti, P., Milazzo, M., Bussotti, S., Molinari, A., Murenu, M., Pais, A., et al. (2008). Italian marine reserve effectiveness: does enforcement matter? Biol. Conserv. 141, 699-709. doi: 10.1016/j.biocon.2007.12.013

Halpern, B. S., Walbridge, S., Selkoe, K. A., Kappel, C. V., Micheli, F., D’Agrosa, C., et al. (2008). A global map of human impact on marine ecosystems. Science 319, 948-952. doi: 10.1126/science. 1149345

Holland, K. N., Kleiber, P., and Kajiura, S. M. (1999). Different residence times of yellowfin tuna, Thunnus albacares, and bigeye tuna, T. obesus, found in mixed aggregations over a seamount. Fish. Bull. 97, 392-395.

Hosegood, P. J., Nimmo-Smith, W. A. M., Proud, R., Adams, K., and Brierley, A. S. (2019). Internal lee waves and baroclinic bores over a tropical seamount shark "hot-spot.". Prog. Oceanogr. 172, 34-50. doi: 10.1016/j.pocean.2019.01.010

Jaine, F. R. A., Couturier, L. I. E., Weeks, S. J., Townsend, K. A., Bennett, M. B., Fiora, K., et al. (2012). When giants turn up: sighting trends, environmental influences and habitat use of the manta ray manta alfredi at a coral Reef. PLoS One 7:e0046170. doi: 10.1371/journal.pone.0046170

Juan-Jordá, M. J., Mosqueira, I., Cooper, A. B., Freire, J., and Dulvy, N. K. (2011). Global population trajectories of tunas and their relatives. Proc. Natl. Acad. Sci. U.S.A. 108, 20650-20655. doi: 10.1073/pnas.1107743108

Juhel, J.-B., Vigliola, L., Mouillot, D., Kulbicki, M., Letessier, T. B., Meeuwig, J. J., et al. (2017). Reef accessibility impairs the protection of sharks. J. Appl. Ecol. 55, 673-683. doi: 10.1111/1365-2664.13007

La Bianca, G., Tillin, H., Hodgson, B., Erni-cassola, G., Howell, K., and Rees, S. (2018). Ascension Island-Natural Capital Assessment: Marine Ecosystem Services Report. Peterborough: JNCC.

Laptikhovsky, V., Naulaerts, J., Clingham, E., Collins, M. A., Cranfield, M., Henry, L., et al. (2020). Comparative feeding strategies of yellowfin tuna around St Helena and adjacent seamounts of the South Atlantic Ocean. J. Appl. Ichthyol. 37, 38-52. doi: 10.1111/jai.14122

Lerner, J. D., Kerstetter, D. W., Prince, E. D., Talaue-McManus, L., Orbeson, E. S., Mariano, A., et al. (2012). Swordfish vertical distribution and habitat use in relation to diel and lunar cycles in the western north atlantic. Trans. Am. Fish. Soc. 142, 95-104

Lester, S. E., Halpern, B. S., Grorud-Colvert, K., Lubchenco, J., Ruttenberg, B. I., Gaines, S. D., et al. (2009). Biological effects within no-take marine reserves: a global synthesis. Mar. Ecol. Prog. Ser. 384, 33-46. doi: 10.3354/meps08029

Letessier, T. B., Mouillot, D., Bouchet, P. J., Vigliola, L., Fernandes, M. C., Thompson, C., et al. (2019). Remote reefs and seamounts are the last refuges for marine predators across the Indo-Pacific. PLoS Biol. 17:e3000366. doi: 10. 1371/journal.pbio. 3000366
Lewin, W. C., Arlinghaus, R., and Mehner, T. (2006). Documented and potential biological impacts of recreational fishing: insights for management and conservation. Rev. Fish. Sci. 14, 305-367. doi: 10.1080/10641260600886455

Lueck, R. G. (1997). Topographically induced mixing around a shallow seamount. Science 276, 1831-1833. doi: 10.1126/science.276.5320.1831

Luiz, O. J., and Edwards, A. J. (2011). Extinction of a shark population in the Archipelago of Saint Paul's Rocks (equatorial Atlantic) inferred from the historical record. Biol. Conserv. 144, 2873-2881. doi: 10.1016/j.biocon.2 011.08.004

Marshall, A., Barreto, R., Carlson, J., Fernando, D., Fordham, S., Francis, M. P., et al. (2019). Mobula mobular. IUCN Red List Threat. Species 2019:e.T110847130A110847142.

Mee, J. A., Otto, S. P., and Pauly, D. (2017). Evolution of movement rate increases the effectiveness of marine reserves for the conservation of pelagic fishes. Evol. Appl. 10, 444-461. doi: 10.1111/eva.12460

Miller, P. I., Scales, K. L., Ingram, S. N., Southall, E. J., and Sims, D. W. (2015). Basking sharks and oceanographic fronts: quantifying associations in the northeast Atlantic. Funct. Ecol. 29, 1099-1109. doi: 10.1111/1365-2435.12423

Montgomery, J. C., Jeffs, A., Simpson, S. D., Meekan, M., and Tindle, C. (2006). Sound as an orientation cue for the pelagic larvae of reef fishes and decapod crustaceans. Adv. Mar. Biol. 51, 143-196. doi: 10.1016/S0065-2881(06)51003-X

Morato, T., Hoyle, S. D., Allain, V., and Nicol, S. J. (2010). Seamounts are hotspots of pelagic biodiversity in the open ocean. Proc. Natl. Acad. Sci. U.S.A. 107, 9707-9711. doi: 10.1073/pnas.0910290107

Morato, T., Miller, P. I., Dunn, D. C., Nicol, S. J., Bowcott, J., and Halpin, P. N. (2016). A perspective on the importance of oceanic fronts in promoting aggregation of visitors to seamounts. Fish Fish. 17, 1227-1233. doi: 10.1111/faf. 12126

Morato, T., Varkey, D. A., Damaso, C., Machete, M., Santos, M., Prieto, R., et al. (2008). Evidence of a seamount effect on aggregating visitors. Mar. Ecol. Prog. Ser. 357, 23-32. doi: 10.3354/meps07269

O’Leary, B. C., Winther-Janson, M., Bainbridge, J. M., Aitken, J., Hawkins, J. P., and Roberts, C. M. (2016). Effective coverage targets for ocean protection. Conserv. Lett. 9, 398-404. doi: 10.1111/conl.12247

Pacoureau, N., Rigby, C. L., Kyne, P. M., Sherley, R. B., Winker, H., Carlson, J. K., et al. (2021). Half a century of global decline in oceanic sharks and rays. Nature 589, 567-571. doi: 10.1038/s41586-020-03173-9

Palomares, M. L. D., and Pauly, D. (2019). SeaLifeBase. Available online at: www.sealifebase.org. (accessed October 1, 2019)

Perrin, W. F. (1985). The former dolphin fishery at St. Helena. Rep. Int. Whal. Commun. 35, 423-428.

Queiroz, N., Humphries, N. E., Noble, L. R., Santos, A. M., and Sims, D. W. (2012). Spatial dynamics and expanded vertical niche of blue sharks in oceanographic fronts reveal habitat targets for conservation. PLoS One 7:e0032374. doi: 10. 1371/journal.pone.0032374

Rigby, C. L., Barreto, R., Carlson, J., Fernando, D., Fordham, S., Francis, M. P., et al. (2019a). Carcharhinus longimanus. IUCN Red List Threat. Species 2019:e.T39374A2911619.

Rigby, C. L., Barreto, R., Carlson, J., Fernando, D., Fordham, S., Francis, M. P., et al. (2019b). Prionace glauca. IUCN Red List Threat. Species 2019: e.T39381A2915850. doi: 10.2305/IUCN.UK.2019-3.RLTS.T39381A2915850.en

Rigby, C. L., Sherman, C. S., Chin, A., and Simpfendorfer, C. (2017). Carcharhinus falciformis. IUCN Red List Threat. Species 2017:e.T39370A117721799. doi: 10. 2305/IUCN.UK.2017-3.RLTS.T39370A117721799.en

Roberts, C. M., Hawkins, J. P., and Gell, F. R. (2005). The role of marine reserves in achieving sustainable fisheries. Philos. Trans. R. Soc. B Biol. Sci. 360, 123-132. doi: $10.1098 /$ rstb.2004.1578

Roff, G., Brown, C. J., Priest, M. A., and Mumby, P. J. (2018). Decline of coastal apex shark populations over the past half century. Commun. Biol. 1, 1-11. doi: 10.1038/s42003-018-0233-1

Rowlands, G., Brown, J., Soule, B., Boluda, P. T., and Rogers, A. D. (2019). Satellite surveillance of fishing vessel activity in the Ascension Island Exclusive Economic Zone and Marine Protected Area. Mar. Policy 101, 39-50. doi: 10. 1016/j.marpol.2018.11.006

Scales, K. L., Miller, P. I., Hawkes, L. A., Ingram, S. N., Sims, D. W., and Votier, S. C. (2014). On the front line: frontal zones as priority at-sea conservation areas for mobile marine vertebrates. J. Appl. Ecol. 51, 1575-1583. doi: 10.1111/13652664.12330 
Seminoff, J. A. (2004). Chelonia mydas. IUCN Red List Threat. Species 2004:e.T4615A11037468. doi: 10.2305/IUCN.UK.2004.RLTS.T4615A1103 7468.en

Thygesen, U. H., Sommer, L., Evans, K., and Patterson, T. A. (2016). Dynamic optimal foraging theory explains vertical migrations of Bigeye tuna. Ecology 97, 1852-1861. doi: 10.1890/15-1130.1

Tickler, D., Meeuwig, J. J., Palomares, M. L., Pauly, D., and Zeller, D. (2018). Far from home: distance patterns of global fishing fleets. Sci. Adv. 4, 4-10. doi: $10.1126 /$ sciadv.aar3279

UK Government (2017). Introducing the Blue Belt Programme. London: UK Government.

Van Haren, H., Hanz, U., de Stigter, H., Mienis, F., and Duineveld, G. (2017). Internal wave turbulence at a biologically rich Mid-Atlantic seamount. PLoS One 12:e189720. doi: 10.1371/journal.pone.0189720

Waldron, A., Adams, V., Allan, J., Arnell, A., Asner, G., Atkinson, S., et al. (2020). Protecting 30\% of the Planet for Nature: Costs, Benefits and Economic Implications. Avaliable online at: https://pure.iiasa.ac.at/id/eprint/16560/1/ Waldron_Report_FINAL_sml.pdf. (accessed August 15, 2019)

Weber, S. B., Weber, N., Ellick, J., Avery, A., Frauenstein, R., Godley, B. J., et al. (2014). Recovery of the South Atlantic's largest green turtle nesting population. Biodivers. Conserv. 23, 3005-3018. doi: 10.1007/s10531-014-0759-6

Weber, S. B., Richardson, A. R., Broderick, A. C., Brown, J., Campanella, F., Godley, B. J., et al. (2018). A Baseline Ecological Assessment of Ascension Island's Shallow-Water Seamounts as Candidate Marine Protected Areas. Ascension Island Government.

Wenzel, L., Laffoley, D., Caillaud, A., and Zuccarino-Crowe, C. (2016). Protecting the World's ocean - the promise of sydney. Aquat. Conserv. Mar. Freshw. Ecosyst. 26, 251-255. doi: 10.1002/aqc.2659

Wilhelm, T. A., Sheppard, C. R. C., Sheppard, A. L. S., Gaymer, C. F., Parks, J., Wagner, D., et al. (2014). Large marine protected areas - advantages and challenges of going big. Aquat. Conserv. Mar. Freshw. Ecosyst. 24, 24-30. doi: $10.1002 /$ aqc. 2499
Woodson, C. B., and Litvin, S. Y. (2015). Ocean fronts drive marine fishery production and biogeochemical cycling. Proc. Natl. Acad. Sci. U.S.A. 112, 1710-1715. doi: 10.1073/pnas.1417 143112

Worm, B., and Tittensor, D. P. (2011). Range contraction in large pelagic predators. Proc. Natl. Acad. Sci. U.S.A. 108, 11942-11947. doi: 10.1073/pnas.110235 3108

Xu, Y., Nieto, K., Teo, S. L. H., McClatchie, S., and Holmes, J. (2017). Influence of fronts on the spatial distribution of albacore tuna (Thunnus alalunga) in the Northeast Pacific over the past 30 years (1982-2011). Prog. Oceanogr. 150, 72-78. doi: 10.1016/j.pocean.2015.04.013

Yen, P. P. W., Sydeman, W. J., and Hyrenbach, K. D. (2004). Marine bird and cetacean associations with bathymetric habitats and shallow-water topographies: implications for trophic transfer and conservation. J. Mar. Syst. 50, 79-99. doi: 10.1016/j.jmarsys.2003. 09.015

Zhao, Q., Stephenson, F., Lundquist, C., Kaschner, K., Jayathilake, D., and Costello, M. J. (2020). Where Marine Protected Areas would best represent $30 \%$ of ocean biodiversity. Biol. Conserv. 244:108536. doi: 10.1016/j.biocon.2020.108536

Conflict of Interest: The authors declare that the research was conducted in the absence of any commercial or financial relationships that could be construed as a potential conflict of interest.

Copyright (C) 2021 Thompson, Meeuwig, Brown, Richardson, Friedlander, Miller and Weber. This is an open-access article distributed under the terms of the Creative Commons Attribution License (CC BY). The use, distribution or reproduction in other forums is permitted, provided the original author(s) and the copyright owner(s) are credited and that the original publication in this journal is cited, in accordance with accepted academic practice. No use, distribution or reproduction is permitted which does not comply with these terms. 